\title{
Unintentionally produced dioxin-like polychlorinated biphenyls during cooking
}

\author{
Shujun Dong, Jiajia Wu, Guorui Liu, Bing Zhang, Minghui Zheng* \\ State Key Laboratory of Environmental Chemistry and Ecotoxicology, Research Center for Eco-Environmental Sciences, Chinese Academy of Sciences, Beijing 100085, China
}

\section{A R T I C L E I N F O}

\section{Article history:}

Received 27 January 2011

Received in revised form

24 April 2011

Accepted 27 April 2011

\section{Keywords:}

PCBs

Cooking

Oil fumes

Sucralose

Chloropropanols

\begin{abstract}
A B S T R A C T
The formation and distribution of dioxin-like polychlorinated biphenyls (dl-PCBs) during cooking was investigated. Concentrations of dl-PCBs in liquid residues, cooked beef, and oil fumes generated during heating were determined by isotope dilution HRGC/HRMS. Although the levels of dl-PCBs in well-done beef were lower compared with those of raw beef, relatively high concentrations of dl-PCBs were detected in the oil fumes produced during heating. This suggests that dl-PCBs in raw beef may have volatilized into the oil fumes during the cooking process. Sucralose and chloropropanols contained in raw materials may have resulted in increased dl-PCB concentrations and the level of toxic equivalents (TEQ) in the oil fumes produced under high temperature during cooking. Concentrations of dl-PCBs did not vary greatly in cooked beef, except when higher levels of chloropropanols were presented in the uncooked raw materials. Results indicate that sucralose and chloropropanols may promote the formation of dl-PCBs during the cooking process. The newly produced dl-PCBs from raw beef cooking were mainly present in oil fumes, which gave rise to high levels of TEQ in oil fumes.
\end{abstract}

(ㄷ) 2011 Elsevier Ltd. All rights reserved.

\section{Introduction}

Polychlorinated biphenyls (PCBs) are typical groups of chlorinated aromatic compounds commonly found in the environment. These compounds are harmful to humans, who generally are exposed to PCBs through the intake of food, especially meat, fish and dairy products. In fact, the 12 congeners of dioxin-like PCBs (dl-PCBs) represent an essential component of the total toxic equivalents (TEQ) in many environmental media, and present considerable health risks. Since cooking is an important process in food preparation, the effects of different cooking processes on the levels of PCBs and other contaminants in foodstuffs has been investigated by several researchers. Some studies have indicated that the typical cooking process reduces PCB levels in green leafy vegetables (Tsutsumi, et al, 2002), fish and beef (Hori, et al, 2005). It has been reported that cooking causes levels of PCBs to be reduced by $30 \%$ in lake trout (Zabik, Booren, Zabik, Welch, \& Humphrey, 1996 ), increased by $14 \%$ in hamburger and $29 \%$ in bacon, and decreased by $33 \%$ in catfish (Schecter, Dellarco, Päpke, \& Olson, 1998). However, such reports have not provided experimental data to explain the decrease or increase in PCBs during the cooking process. Recently, the effects of several cooking processes were evaluated in various foodstuffs in Catalonia (Spain), and the

\footnotetext{
* Corresponding author. Tel./fax: +86 1062849172

E-mail address: zhengmh@rcees.ac.cn (M. Zheng).
}

researchers suggested that cooking processes have limited value in reducing concentrations of PCBs in food (Perelló, Martí-Cid, Castell, Llobet, \& Domingo, 2010). Since these studies mainly focused on the alteration of PCB levels in uncooked and cooked foodstuffs, information on the distribution and formation of PCBs during the cooking process have not been discussed.

Cooking and food processing at high temperature have been shown to generate polycyclic aromatic hydrocarbons (PAHs), which can be formed through grilling and smoking of food (Farhadian, Jinap, Abas, \& Sakar, 2010; Stolyhwo \& Sikorski, 2005). PAHs also are detected in oil fumes released during the cooking process (Chiang, Wu, \& Ko, 1999). The formation of PCBs may take place by the reaction of PAHs with chlorine at presence of catalysts during the cooking process under certain thermal conditions (Iino, Imagawa, Takeuchi, \& Sadakata, 1999; Weber et al, 2001). Indeed, many cooking processes are conducted at high temperature, and the resulting complex foodstuff matrices can provide carbon sources, which form PCBs. In addition, there are some kinds of metallic elements, such as copper, zinc and iron, which exist in foodstuffs or cooking utensils and may act as catalysts. Moreover, various kinds of chlorine-containing compounds may be found in foodstuffs, and in food additives and flavorings.

In this study, two kinds of chlorine-containing compounds that may be present during the cooking process were investigated. These compounds commonly are used intentionally or unintentionally in cooking processes. Sucralose $\left(4,1^{\prime}, 6^{\prime}\right.$-trichloro- $4,1^{\prime}, 6^{\prime}$-trideoxygalactosucrose, TGS), is an artificial sweetener derived from 
native sucrose, and can be found in hundreds of food and beverage products as a substitute for sugar (Grotz \& Munro, 2009). FAO/WHO regulates the maximum addition of sucralose in different kinds of foodstuffs, and suggests that the use of this product should range from 0.15 to $1.5 \mathrm{~g} / \mathrm{kg}$. Chloropropanols (3-monochloropropane1,2-diol, 3-MCPD or 1,3-dichloropropane-2-ol, 1,3-DCP) are produced as byproducts by adding hydrochloric acid to speed up the reaction of soy protein with lipids at high temperatures, and is found in soy sauce (Collier, Cromie, \& Davies, 1991). Specifications of $1 \mathrm{mg} /$ $\mathrm{kg} 3-\mathrm{MCPD}$ and $0.05 \mathrm{mg} / \mathrm{kg}$ 1,3-DCP in acid-hydrolyzed vegetable proteins (on a dry basis) were established by the Food Chemical Codex in 1997 (JFSP, 2001). Some literatures have indicated that the decomposition of sucralose and chloropropanols might occur under high temperature (Rahn \& Yaylayan, 2010; Svejkovska, Dolezal, \& Velisek, 2006). A series of previous experiments using different levels of sucralose and 1,3-DCP have shown that chlorine appears to play an essential role in the formation of $\mathrm{C}-\mathrm{Cl}$ bonds, and the subsequent PCBs formed. Raw beef and soybeans oil purchased from local markets were selected as typical raw materials for cooking. Concentrations of dl-PCBs in oil and beef were examined before and after cooking. In addition, oil fumes generated during the cooking process were also collected, to identify the formation and distribution of PCBs in the cooking process.

\section{Materials and methods}

\subsection{Cooking process and sampling}

All organic solvents used in the experiments were pesticide residue grade, and were obtained from J.T. Baker (NJ, USA). Sucralose (purity $>98 \%$ ) was purchased from Sigma-Aldrich, Inc. (MO, USA) and 1,3-DCP (purity >98\%) from Alfa Aesar (Ward Hill, MA, USA). A piece of fresh beef was purchased at a local market in September 2010. Lean muscle tissue was minced thoroughly through a commercial meat mincer. Fig. 1 shows a schematic of the cooking system used in this study. A total of $50 \mathrm{~g}$ of soybean oil and $150 \mathrm{~g}$ of beef sample were put into a stainless steel bowl to provide one subsample. Oil, which is commonly used in cooking, was added to avoid overcooking the beef. Every sub-sample was heated for $15 \mathrm{~min}$ on an electric stove. An air pump, with an air flow rate of $25 \mathrm{~L} / \mathrm{min}$, was turned on during heating and left running for an additional $10 \mathrm{~min}$ during cooling to trap oil fumes. One analytical sample to quantify the trace dl-PCBs was composed of four sub-samples of oil fumes produced under the same conditions. Approximately $40 \mathrm{~g}$ XAD-2 resin (Supelco, USA) was used for each sample to absorb the oil fumes. The XAD-2 resin was pre-extracted in dichloromethane and hexane for $48 \mathrm{~h}$, stored in dichloromethane, and $\mathrm{N}_{2}$-dried prior to use. The liquid residues of four sub-samples remaining after cooking were poured out immediately and mixed as one analytical sample of liquid residue, while the four cooked beef sub-samples were ground and combined as one analytical sample of the cooked beef.

The raw materials used in different experiments are summarized in Table 1. Experiment trials B0 and B1 were carried out to investigate the effect of oil in the cooking process. Four levels of sucralose (BS set) and five levels of 1,3-DCP (BP set) were added to the raw materials, respectively. The temperatures of the different parts of the cooking system were recorded with thermo sensors. The temperature of the plate between the electric stove and the bowl was kept at $400{ }^{\circ} \mathrm{C}$ during the cooking process. The highest foodstuff temperature achieved during cooking was $160 \pm 5^{\circ} \mathrm{C}$. In addition, the temperature of the oil fumes generated during the cooking process was about $105^{\circ} \mathrm{C}$.

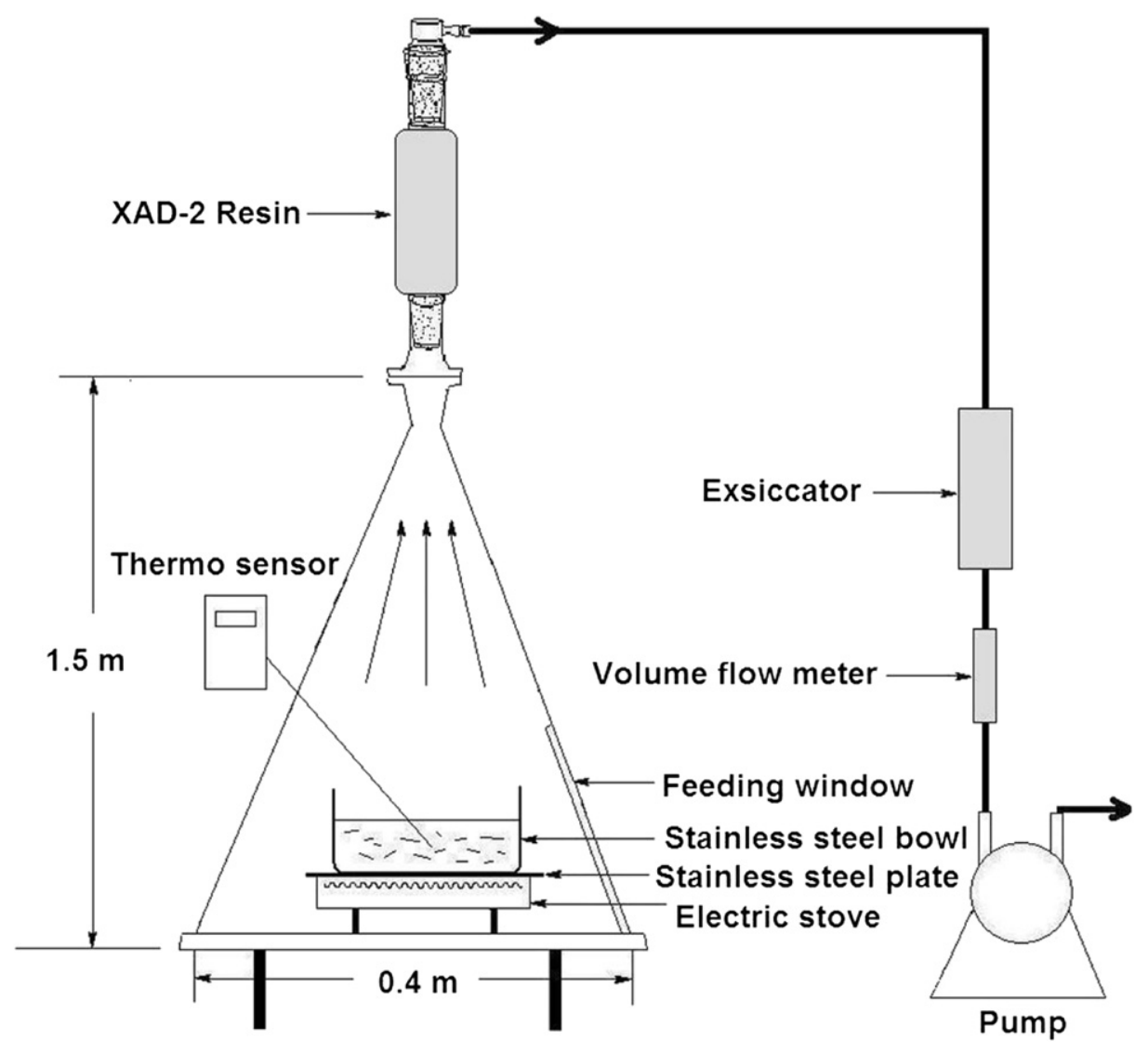

Fig. 1. Schematic of the cooking system. 
Table 1

Information on raw materials employed in the cooking process.

\begin{tabular}{llllll}
\hline \multirow{2}{*}{ Experiment ID } & \multicolumn{4}{l}{ Raw materials } & \\
\cline { 3 - 6 } & & Beef/g & Soybean oil/g & Additive/g & \\
\cline { 3 - 6 } & & & & Sucralose/g & $1,3-\mathrm{DCP} / \mathrm{g}$ \\
\hline BS set & B0 & 601.3 & - & - & - \\
& B1 & 601.7 & 202.7 & - & - \\
BS set & BS1 & 606.5 & 201.9 & $4.2 \times 10^{-2}$ & - \\
& BS2 & 601.7 & 204.2 & 0.4 & - \\
& BS3 & 601.5 & 201.9 & 4.1 & - \\
& BS4 & 603.2 & 206.4 & 45.0 & - \\
& & & & & $4.1 \times 10^{-5}$ \\
BP set & BP1 & 599.4 & 202.2 & - & $4.0 \times 10^{-3}$ \\
& BP2 & 598.7 & 201.9 & - & 0.4 \\
& BP3 & 602.1 & 199.2 & - & 4.0 \\
& BP4 & 599.8 & 200.6 & - & 40.2 \\
\hline
\end{tabular}

\subsection{Analytical methods}

Twelve dl-PCBs congeners were analyzed with a US EPA Method 1668 A. Before spiking the samples with ${ }^{13} \mathrm{C}_{12}$-labeled PCBs (internal standards with known concentration; Wellington Laboratories, Guelph, Canada), the homogenized beef samples were blended with equal weights of anhydrous sodium sulfate. In addition, the oil fume samples were extracted directly after adding the internal standards. Both beef and oil fume samples were Soxhlet extracted with $250 \mathrm{~mL}$ hexane/acetone for about $24 \mathrm{~h}$, and concentrated for dl-PCBs determination. Without extraction, the liquid residue was obtained as follows.

The concentrated extract and liquid residue were first cleaned by gel permeation chromatography (GPC), and then by a series of adsorption chromatography steps, including use of acid silica and multilayer silica columns. A basic alumina column was employed to separate PCBs from interfering components. Prior to injection, ${ }^{13} \mathrm{C}_{12}$ labeled PCBs, with a known standard concentration (Wellington Laboratories, Guelph, Canada) were added to the concentrated extracts for recovery calculations.

The 12 dl-PCB congeners were analyzed by an Agilent 6890 gas chromatograph equipped with a DB-5 MS fused-silica column $(60 \mathrm{~m} \times 0.25 \mathrm{~mm}$ i.d. $\times 0.25 \mu \mathrm{m})$ and coupled with a Waters Autospec Ultima high-resolution mass spectrometer. Two selected ions of molecular ion clusters were measured by the mass spectrometer in selected-ion monitoring mode at a resolution of $\geq 10,000$.

\subsection{Quality control and assurance}

Given the complicated cooking processes, experiments BS4 and BP5, with chlorine-containing compounds at the highest levels, as well as experiment B1 without any chlorine-containing compounds added, were run in duplicate. Variations of the duplicate analyses were within $30 \%$ of each other. The recoveries of $12{ }^{13} \mathrm{C}_{12}$-labeled dl-PCB congeners were in the range of $60-130 \%$ for all matrices. TEQs were calculated using WHO-TEF (2005). The limits of detection (LOD, fresh weight) of dl-PCBs in this study were $0.001-0.07 \mathrm{pg} / \mathrm{g}$. The concentrations of those congeners under LOD were replaced by half of the LOD.

A blank test was carried out every eight samples to calibrate the system. To monitor the cross contamination, air in the cooking system was gathered for 100 min between every two groups as field blanks ( $n=12)$ without any raw materials added. In all the blank samples CB 77, CB 105 and CB 118 were the most prevalent interferences. Nevertheless, levels of the three congeners in the method

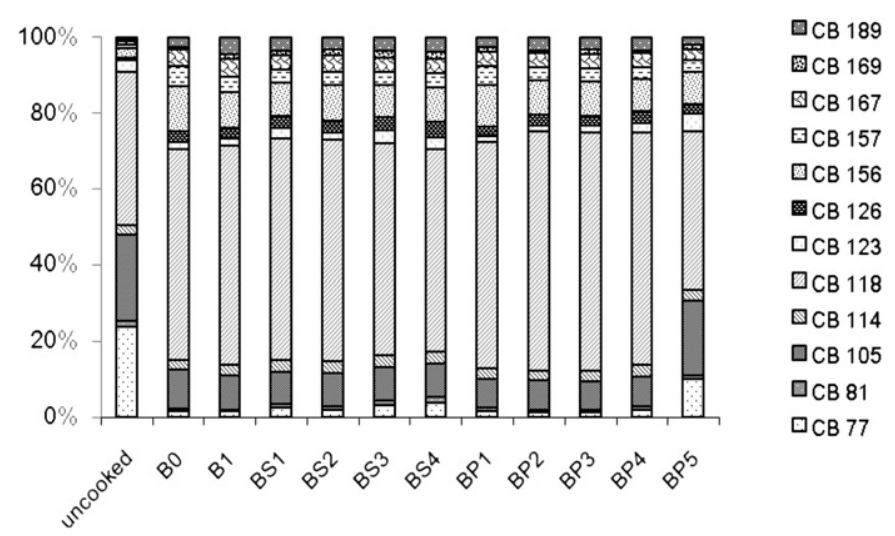

Fig. 2. Patterns of dl-PCB congeners in uncooked and cooked beef.

and the field blanks had less than $10 \%$ of the three congeners in the liquid residue, cooked beef or oil fume samples, correspondingly. Thus, there was no blank correction needed in these analyses.

\section{Results and discussion}

\subsection{Concentrations of dl-PCBs in raw and cooked beef}

Weight decreases of beef samples after cooking were observed in all experiments. In order to correct for weight loss, concentrations of dl-PCBs in all samples were calculated on the basis of the fresh weights. The dl-PCB congeners in raw and cooked beef are shown in Fig. 2. The concentrations of CB 77 (17.55 pg/g), CB 105 (16.52 pg/g), and CB $118(29.34 \mathrm{pg} / \mathrm{g})$ in raw beef were relatively higher than those of the other dl-PCB congeners $(0.17-2.18 \mathrm{pg} / \mathrm{g})$. These results are in agreement with Hori et al. (2005). Furthermore, the total TEQ level of the raw beef $(0.058 \mathrm{pg}$ WHO-TEQ/g) was higher than that reported by a total diet study in Taiwan $(0.011 \mathrm{pg}$ WHO-TEQ/g) (Chen, Su, Hsu, Liao, \& Lee, 2008).

Concentrations of $12 \mathrm{dl}-\mathrm{PCB}$ congeners in cooked beef samples decreased by more than $50 \%$ after cooking. In fact, the levels of $\mathrm{CB}$ 77, CB 105 and CB 118 declined 85-90\%. Compared with experiment B0, the presence of oil in experiment B1 did not significantly affect the levels of dl-PCBs in the cooked beef. In experiments BS and BP, the concentrations of dl-PCBs in cooked beef were maintained at the same level as that in experiment B1. An exception was experiment BP5, in which 1,3-DCP was present in the reaction

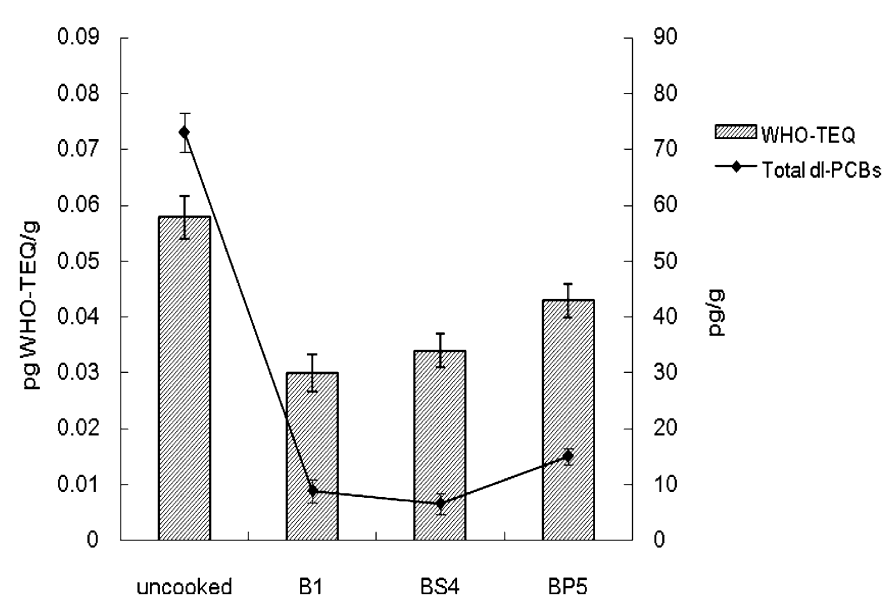

Fig. 3. TEQ levels and total dl-PCB concentrations of uncooked and cooked beef. 


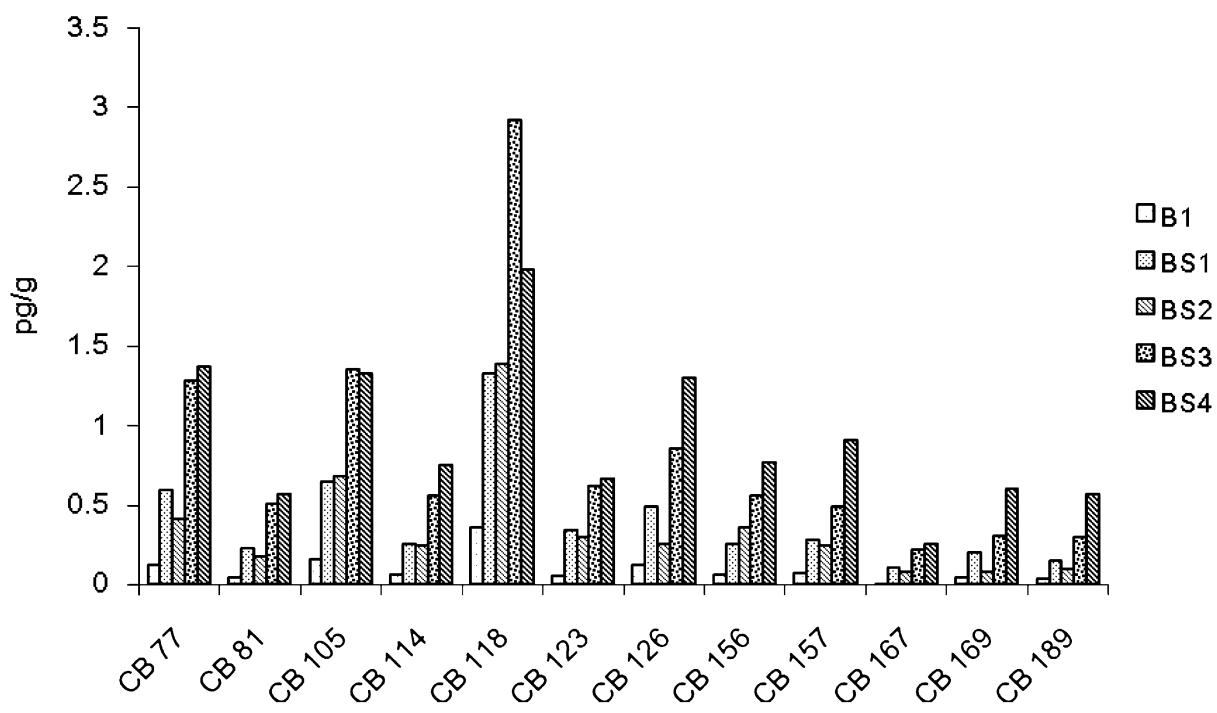

Fig. 4. Profile of $12 \mathrm{dl}-\mathrm{PCBs}$ in oil fumes.

system. In experiment BP5, the concentrations of dl-PCBs in cooked beef were the highest across all experiments, but did not exceed the dl-PCB levels in uncooked beef.

Fig. 2 shows that the cooking process could significantly change the profile of dl-PCB congeners in beef samples. Before cooking, CB 77, CB 105 and CB 118 made up nearly 90\% of total dl-PCBs concentrations. After cooking, the percentage of $\mathrm{CB} 77$ declined sharply, while the percentage of CB 156 increased. Interestingly, the patterns of dl-PCBs in all cooked beef were similar, except for that in experiment BP5, where CB 105 in cooked beef was relatively higher than in the other experiments, and reflected a different distribution of dl-PCBs.

TEQ levels of beef samples also declined after cooking. In all raw and cooked beef samples, CB 126 contributed preferentially to the TEQs, which made up more than $85 \%$ of the total TEQs. CB 169 was the secondary contributor to the total TEQ. The toxicity of CB 126 and CB 169 made up 93\% of the TEQ value in raw beef, while more than $98 \%$ was found in cooked beef. In Fig. 3, it is evident that the levels of TEQ in cooked beef in BS4 (45 g sucralose contained) did not significantly increase, but greatly increased in experiment BP5 (40.2 g 1,3-DCP contained). This means that a high level of 1,3-DCP existed in raw beef, and not only enhanced the concentrations of individual dl-PCB congeners and the TEQ level, but also changed the profiles of dl-PCBs congeners in cooked beef. This result indicates that dl-PCBs formed in beef in the presence of 1,3-DCP during the cooking process.

\subsection{Concentrations of $d l-P C B s$ in oil fumes}

Twelve dl-PCB congeners were detected in the oil fumes. Concentrations of individual dl-PCB congeners in the oil fumes of experiments $\mathrm{B} 0$ and $\mathrm{B} 1$ were similar. These results indicate that the influence of oil on the concentrations of dl-PCBs in the oil fumes was not significant. Oil fume dl-PCBs may accumulate through their volatilization from raw beef during heating. Thus, the dl-PCBs that transformed from the solid to the gas phase are accompanied by water and lipids. Hence, transformation of PCBs from solid raw

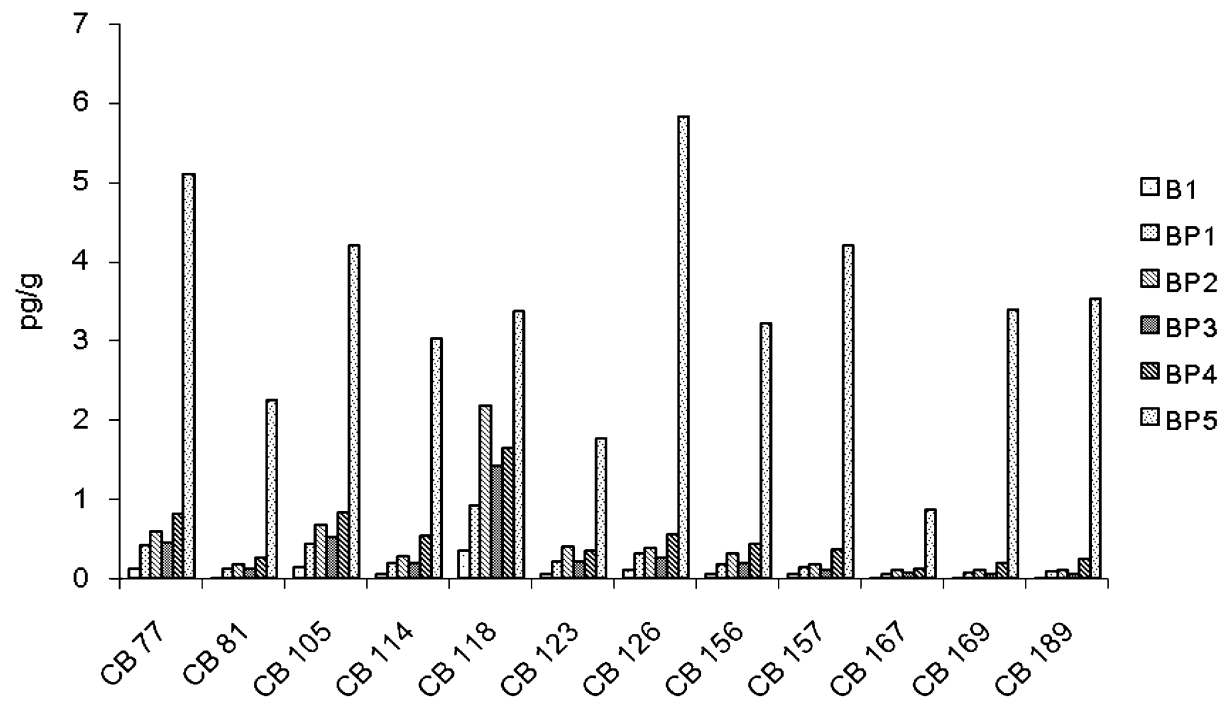

Fig. 5. Profile of 12 dl-PCBs in oil fumes. 


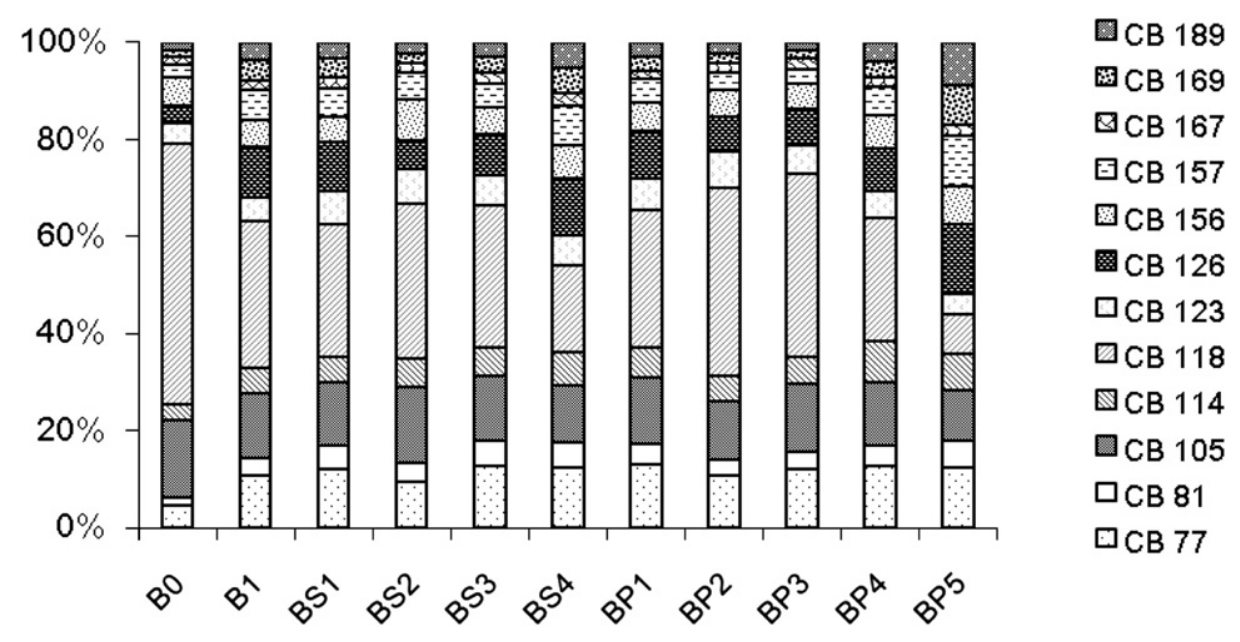

Fig. 6. Patterns of dl-PCBs congeners in oil fumes.

materials to oil fumes during the cooking process was established clearly in this study.

Investigations on $\mathrm{PCBs}$ emissions during the cooking process have not been reported previously. Figs. 4 and 5 indicate that sucralose or 1,3-DCP contained in raw beef could increase the levels of dl-PCBs in oil fumes. Compared with oil fumes released in experiment $B 1$, all the 12 dl-PCB congeners in oil fumes increased in experiment BS and BP. Even in experiment BS1, with the addition of only $0.0042 \mathrm{~g}$ sucralose, the concentrations of total dl-PCBs increased significantly. In addition, TEQ values increased by three times compared to those in experiment B1 (0.014 pg WHO-TEQ/g). Generally, with the increased amount of sucralose, the formation of total dl-PCBs also increased. As in cooked beef, CBs 126 and 169 were the primary contributors of the total TEQs in oil fumes. Surprisingly, when $40.2 \mathrm{~g}$ 1,3-DCP was present in raw beef of experiment BP5, the concentrations of dl-PCB congeners in oil fumes, as well as TEQ levels ( $0.688 \mathrm{pg} \mathrm{WHO-TEQ/g),} \mathrm{were}$ much higher. Results of this study suggest that sucralose or 1,3-DCP in raw beef could act as chlorine sources and promote the formation of dl-PCBs in oil fumes.

Fig. 6 shows that oil used in cooking could significantly change the patterns of $12 \mathrm{dl}-\mathrm{PCBs}$ in the oil fumes. Compared with experiment $\mathrm{B} 0$ without oil, the percentage of $\mathrm{CB} 118$ declined sharply in other experiments. In experiments BS and BP, the patterns of dlPCBs in oil fumes were similar, except for that in experiments BS4 and BP5. Although the pattern of dl-PCBs in oil fume of experiment B0 was similar with most patterns in cooked beef, the patterns of $12 \mathrm{dl}$-PCBs in other oil fumes were quite unlike result from the decreasing percentage of CB 118.

\subsection{Phase transformation of dl-PCBs during the cooking process}

Since soybean oil was employed in the cooking process, concentrations of dl-PCBs in soybean oil also were determined before cooking. The total TEQ level of soybean oil $(0.003 \mathrm{pg}$ WHO-TEQ/g) was found to be lower than that of olive oil $(0.04 \mathrm{pg}$ WHO-TEQ $/ \mathrm{g})$ in a survey of German markets (Papadopoulos, Vassiliadou, Costopoulou, Papanicolaou, \& Leondiadis, 2004). The level of soybean oil also was lower than that of olive oil ( $0.1705 \mathrm{pg}$ WHO-TEQ/ g) used in the study of Perelló et al. (2010).

To investigate the transformation of dl-PCBs during the cooking process, concentrations of dl-PCBs in liquid residues also were analyzed. Although the concentrations of $12 \mathrm{dl}-\mathrm{PCB}$ congeners in liquid residues increased compared with those of the original soybean oil, TEQ levels were all within $0.010 \mathrm{pg}$ WHO-TEQ/g. It has been assumed that the removal or transference of PCBs in beef tissue may occur by thermal decomposition and volatilization (Moya, Garrahan, \& Durell, 1998). Since high levels of dl-PCBs were detected in oil fumes of this study, volatilization was confirmed. Generally, dl-PCBs could be transferred from raw beef to oil fumes and liquid residues during the cooking process. This indicates that volatilization was the main pathway for removal of PCBs from beef in the cooking process.

As mentioned above, sucralose or 1,3-DCP could promote production of PCBs in oil fumes, and TEQ levels of oil fumes may increase significantly when sucralose or 1,3-DCP is added. However, within the limitations of the cooking system simulation of this study, the dl-PCBs monitored here did not reach mass balance. Further studies to investigate the decomposition and transformation of PCBs during cooking processes without cooking simulation biases will need to be conducted in the future.

\section{Conclusions}

This study provides a general description of the formation and transformation of dl-PCBs during cooking. The formation of dl-PCBs was observed mainly in oil fumes with sucralose or 1,3-DCP as additives during the cooking process, in which case dl-PCBs could transfer from the raw beef to the oil fumes. Sucralose and 1,3-DCP are only model chemicals for chlorine-containing compounds, which may be used during daily cooking processes. Thus, appropriate use of chlorine-containing additives and flavorings during cooking could help reduce the risk of human exposure to dl-PCBs.

\section{Acknowledgments}

This study was supported by the National Nature Science Foundation of China (20777086 and 20921063).

\section{References}

Chen, H. L., Su, H. J., Hsu, J. F. Liao, P. C., \& Lee, C. C. (2008). High variation of PCDDs, $\mathrm{PCDF}$, and dioxin-like $\mathrm{PCBs}$ ratio in cooked food from the first total diet survey in Taiwan. Chemosphere, 70, 673-681.

Chiang, T.-A., Wu, P.-F., \& Ko, Y.-C. (1999). Identification of carcinogens in cooking oil fumes. Environmental Research, 81, 18-22.

Collier, P. D., Cromie, D. D. O., \& Davies, A. P. (1991). Mechanism of formation of chloropropanols present in protein hydrolysates. Journal of the American Oil Chemists' Society, 68, 785-790.

JFSP (Joint FAO/WHO Food Standards Programme). (2001). Position paper on chloropropanols for the thirty-third session of the codex committee on food additives and contaminants. 
Farhadian, A., Jinap, S., Abas, F., \& Sakar, Z. I. (2010). Determination of polycyclic aromatic hydrocarbons in grilled meat. Food Control, 21, 606-610.

Grotz, V. L., \& Munro, I. C. (2009). An overview of the safety of sucralose. Regulatory Toxicology and Pharmacology, 55, 1-5.

Hori, T., Nakagawa, R., Tobiishi, K., Iida, T., Tsutsumi, T., Sasaki, K., et al. (2005). Effects of cooking on concentrations of polychlorinated dibenzo-p-dioxins and related compounds in fish and meat. Journal of Agricultural and Food Chemistry, 53, 8820-8828.

Iino, F., Imagawa, T. Takeuchi, M., \& Sadakata, M. (1999). De novo synthesis mechanism of polychlorinated dibenzofurans from polycyclic aromatic hydrocarbons and the characteristic isomers of polychlorinated naphthalenes. Environmental Science \& Technology, 33, 1038-1043.

Moya, J., Garrahan, K. G., Poston, T. M., \& Durell, G. S. (1998). Effects of cooking on levels of PCBs in the Fillets of Winter Flounder. Bulletin of Environmental Contamination and Toxicology, 60, 845-851.

Papadopoulos, A., Vassiliadou, I., Costopoulou, D., Papanicolaou, C. \& Leondiadis, L. (2004). Levels of dioxins and dioxin-like PCBs in food samples on the Greek market. Chemosphere, 57, 413-419.

Perelló, G., Martí-Cid, R., Castell, V., Llobet, J. M., \& Domingo, J. L. (2010). Influence of various cooking processes on the concentrations of PCDD/PCDFs, PCBs and PCDEs in foods. Food Control, 21, 178-185.
Rahn, A., \& Yaylayan, V. A. (2010). Thermal degradation of sucralose and its potential in generating chloropropanols in the presence of glycerol. Food Chemistry, 118 56-61.

Schecter, A., Dellarco, M., Päpke, O., \& Olson, J. (1998). A comparison of dioxins, dibenzofurans and coplanar PCBS in uncooked and broiled ground beef, catfish and bacon. Chemosphere, 37, 1723-1730.

Stolyhwo, A., \& Sikorski, Z. E. (2005). Polycyclic aromatic hydrocarbons in smoked fish - a critical review. Food Chemistry, 91, 303-311.

Svejkovska, B., Dolezal, M., \& Velisek, J. (2006). Formation and decomposition of 3 chloropropane-1,2-diol esters in models simulating processed foods. Czech Journal Food Science, 24, 172-179.

Tsutsumi, T., Iida, T., Hori, T., Nakagawa, R., Tobiishi, K., Yanagi, T., et al. (2002) Recent survey and effects of cooking processes on levels of PCDDs, PCDFs and Co-PCBs in leafy vegetables in Japan. Chemosphere, 46, 1443-1449.

Weber, R., Iino, F., Imagawa, T., Takeuchi, M., Sakurai, T., \& Sadakata, M. (2001) Formation of PCDF, PCDD, PCB, and PCN in de novo synthesis from $\mathrm{PAH}$ : mechanistic aspects and correlation to fluidized bed incinerators. Chemosphere, 44, 1429-1438.

Zabik, M. E., Booren, A., Zabik, M. J., Welch, R., \& Humphrey, H. (1996). Pesticide residues, PCBs and PAHs in baked, charbroiled, salt boiled and oil fumed great lakes lake trout. Food Chemistry, 55, 231-239. 